\title{
La tipografía y el libro en Occidente: el primer producto moderno y globalizador
}

\section{Resumen}

Se analizan el proceso de concreción y normalización en la creación de un producto moderno como es el libro y el diseño tipográfico inherente al propio producto, así como la gestación del primer producto globalizado. Este estudio se lleva a cabo haciendo un recorrido histórico que nos permite contrastar diferencias fundamentales entre los códices de diferentes culturas y el libro en el siglo XVI, y abordar los antecedentes del diseño editorial y tipográfico.

Palabras clave: libro, tipografía, incunable, marca, imprenta.

\section{The typography and the book in the western world: the first modern and global product}

\section{Abstract}

The study analyses the process of realization and standardization in the creation of a modern product as it is the book, the typographic design inherent in the product itself, as well as the gestation of the first globalized product. This study is takes to out doing a tour historic that us allows contrast differences fundamental among them codices of them different cultures and the book in the century XVI, as well as the history of the editorial and typographic design.

Keywords: book, typography, incunabulum, brand, print.

1 Profesora e Investigadora en la Universitat Politècnica de València. Doctora en Adecuación de Marca, Envase y Producto (Cum Laude) y Máster en Ingeniería del Diseño por la Escuela Técnica Superior de Ingeniería del Diseño de la UPV y Licenciada en Bellas Artes por la Universidad de Barcelona. Comisaria de exposiciones de Diseño Gráfico. E-mail: soesfer@upv.es 


\section{INTRODUCCIÓN}

El libro hoy en día es una fuente de creación de valor cultural. Sin embargo, la historia revela que su estructura y ordenación de la información, uso de fuentes tipográficas, retículas constructivas, uso de marcas de impresión y otros elementos provienen de métodos aplicados. Sus variantes provienen de fuentes históricas que lo hicieron evolucionar a medida que la propia sociedad evolucionaba. La cual debía dar respuesta a los nuevos procesos y procedimientos de la incipiente y creciente economía de mercado.

La aparición de un sistema mecanizado de impresión supuso la proyección nuevas metodologías que fueron, a su vez, evolucionando hasta concretarse en un sistema de comunicación bien articulado.

En este análisis veremos el cambio sustancial que supuso el paso de un sistema de comunicación basado en el uso de códices, a un sistema de comunicación fundado en el uso de libros, que eran generados con tipos móviles y métodos constructivos rigurosos enfocados a proporcionar mayor claridad en la lectura, facilitando de este modo la legibilidad.

Por otro lado, veremos como las evoluciones económicas y políticas, así como las tecnológicas y sociales, afectan en la manera de producir y consumir material escrito en la Edad Moderna. Se describe como las formas gráficas y tipográficas se simplifican y el surgimiento de una disciplina que tiene como finalidad concretar una metodología proyectiva que normalice un producto realizado en serie. De igual modo, se analiza la relevancia de comunicar a través de la creación de libros en diferentes idiomas, que surgen como necesidad de aportar información detallada sobre temas relevantes, y que sirven para proyectar una manera de concebir y de pensar el mundo.

De hecho, con la invención de la imprenta de tipos móviles² se produce un cambio radical en la producción de este tipo de productos. Hasta entonces eran realizados artesanalmente, los llamados códices o codex (del latín, bloque de madera). En la Edad Media los realizaban los monjes escribas y copistas en el Scriptorium, los cuales escribían y pintaban los elementos que en ellos aparecían, utilizando igualmente tablas xilográficas ${ }^{3}$ (siglo XIV y la primera mitad del siglo XV). Cabe decir, que estaban conformados por hojas rectangulares, de diferentes tipos de materiales, como el pergamino, el papiro y el papel. Todos en su conjunto conformaban cuadernillos o quaterni, que eran cosidos y protegidos por una encuadernación exterior.

Actualmente este estilo de escritura ha derivado en un estilo específico de fuente tipográfica, como son la familia de fuentes rotuladas, donde se encuentran las góticas y caligráficas, muchas de ellas, como indicamos, de origen medieval. Con respecto a las ilustraciones e imágenes su uso difiere con respecto a otras culturas. Así, por ejemplo, encontramos que el uso de letras antropomórficas y de la letra capital ornamentada sufre variaciones de tamaño en diferentes épocas. Lo más destacable es la evolución del uso de la ornamentación,

2 Nos referimos a la llevada a cabo por Johannes Gutenberg (Maguncia, Alemania) aproximadamente hacia el 1441. Aunque otros estudios sitúan la invención original de los tipos móviles, hechos en arcilla y después en estaño, a Pi Shêng aproximadamente en el año 1045 en China (Needham, 2004).

3 Se trata de un grabado en madera, este procedimiento consistía en grabar en la tabla toda una página que se imprimía en negro y que posteriormente se coloreaba a mano. 
que progresa desde una función asignada a la composición en el periodo románico, hacia una aplicación puramente estética en el periodo gótico (Hernández, 2015).

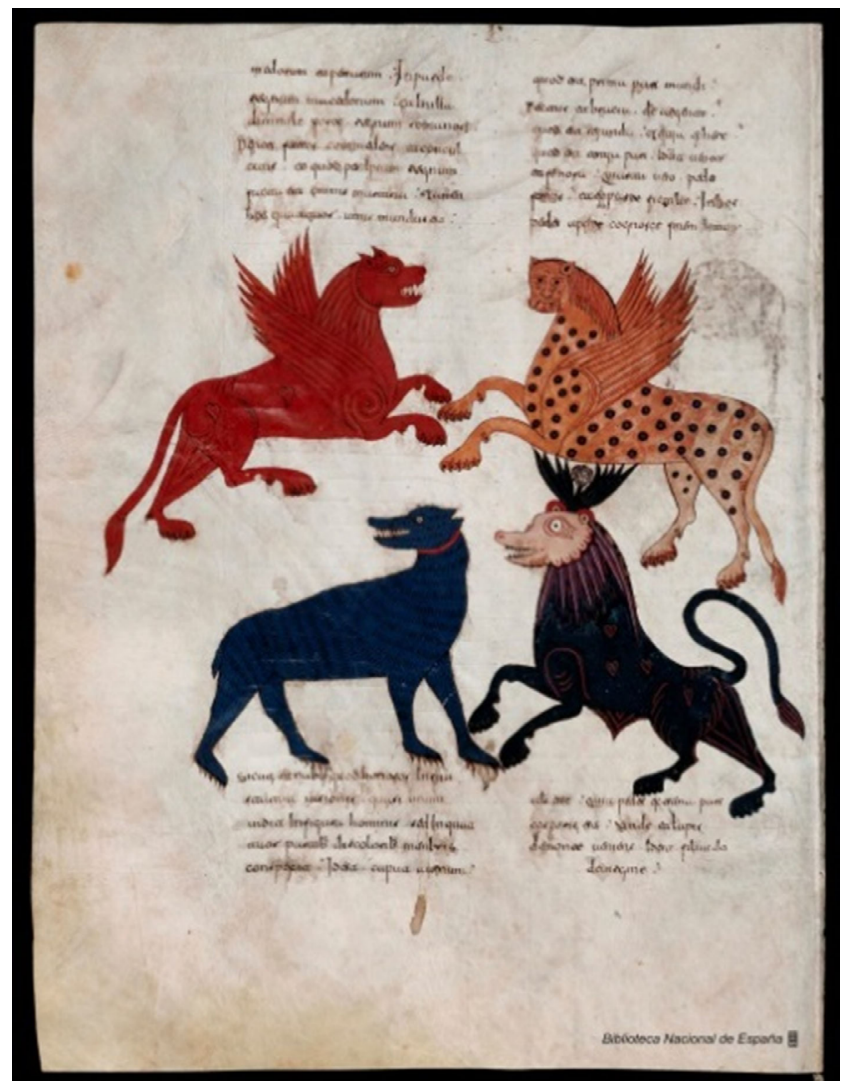

Fig. 1. Códice del Beato de Liébana del año 776, la versión definitiva es del año $786^{4}$. Página del Beato de Liébana: Códice de Fernando I y Dña. Sancha (s. XI). Biblioteca Nacional de España.

Hay que recordar que al igual de los códices medievales tienen sus fuentes en el mundo romano y griego, a través de los pergaminos y códices de pergamino romanos; existen códices producidos en otras lenguas como las escritas en hebreo o en árabe. Además de los elaborados en otras partes del mundo como los códices chinos o los códices precolombinos, cuyas características difieren de los medievales europeos y del mediterráneo, tanto en su material de fabricación como en su concepción. Por citar algún ejemplo notorio, vemos como los códices precolombinos estaban hechos de piel de ciervo. La piel se plegaba en formato acordeón y estaban encuadernados con tablas de madera, entre ellos están el Códice Cortesiano o el Códice Periano (Nayar, 2009).

4 Conocidos como Los Beatos los manuscritos de los siglos X y XI, más o menos abundantemente ilustrados, recogen el Apocalipsis de San Juan y los 'Comentarios' redactados por el Beato de Liébana en el siglo VIII. PID: bdh0000051522 <http://bdh-rd.bne.es> (29/10/2016). Otros códices relevantes son Codex Calixtinus (Santiago de Compostela, siglo XII), se trata de una guía del Camino de Santiago. Codex Aureus (Luxemburgo, 1043), que se encuentra en la Biblioteca del Monasterio de San Lorenzo del Escorial. Codex Emilianense (San Millán de la Cogolla, La Rioja, siglo X) que se consideran la primera muestra de la lengua romance peninsular castellana. Cantigas de Santa María, de Alfonso X El Sabio (Toledo, 1284), muestra de la lírica medieval, de la música y de las costumbres de la época. El Apocalipsis figurado, de los duques de Saboya (Francia 1428-1480), compuesto de 49 páginas de pergamino con ilustraciones de estilo gótico francés. Cantar de Mio Cid (Castilla, siglo XI), una de las obras cumbre de la literatura castellana y muestra de la literatura épica. 


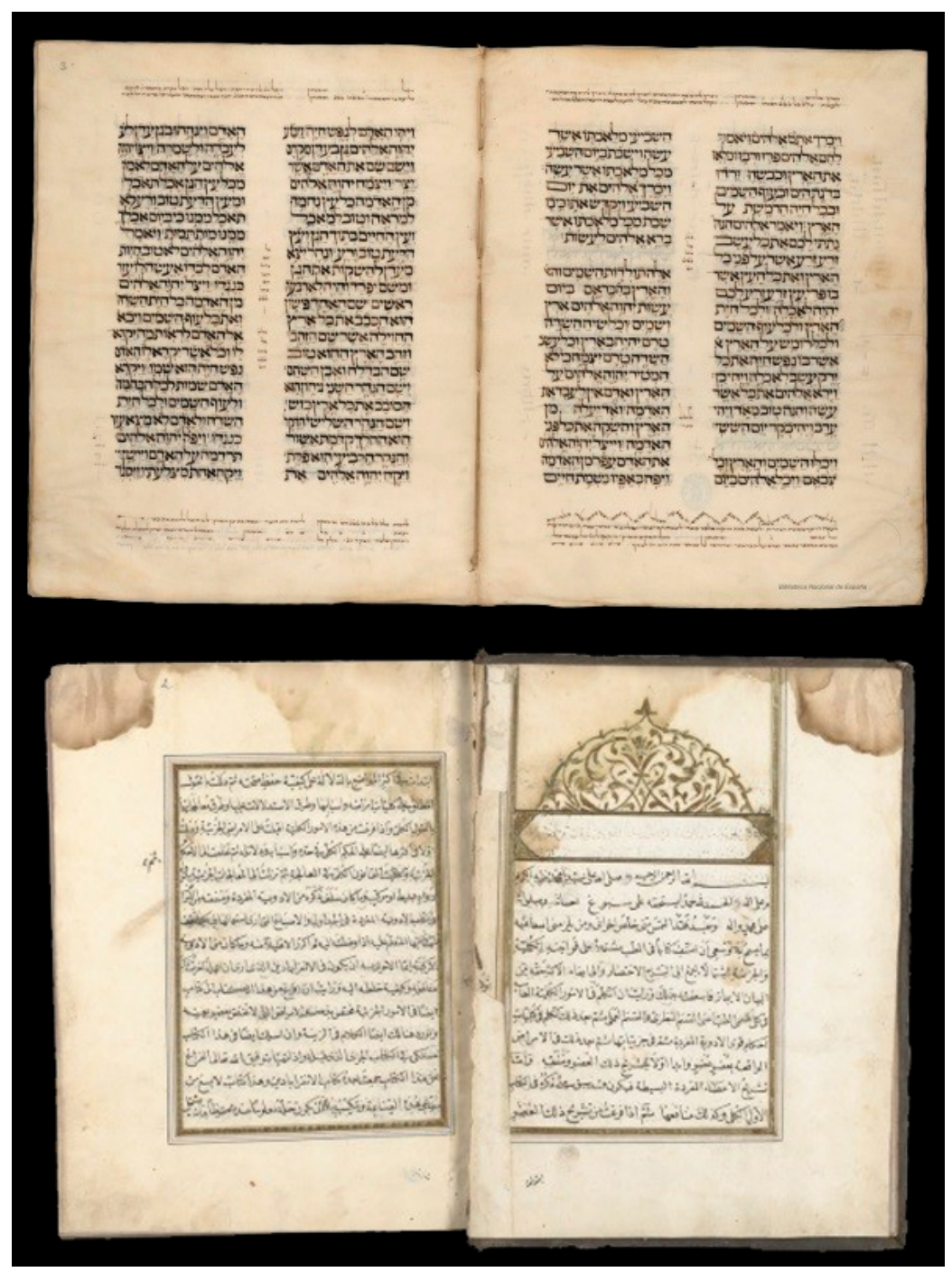

Fig. 2. Arriba: Biblia hebrea litúrgica. Toledo S. XIII. La escritura sefardí cuadrada y cursiva en la masora. Biblioteca Nacional de España 5 . Abajo: Canon de Medicina de Avicena (980-1037). Una de sus peculiaridades es que se lee de derecha a izquierda con respecto a las lenguas de origen latino. Biblioteca Nacional Mundial ${ }^{6}$.

Una de las características y peculiaridades que se puede atribuir es la expresión de una cultura propia. Además de la mencionada en su método de confección, otra particularidad radica en que se desplegaba para su lectura. Los códices mexicanos como Codex Borgia, Tatlecococ, Baranda o Tudela, estaban conformados por glifos o ideogramas, se leían de izquierda a derecha o de derecha a izquierda, y aunque la lectura es variable, hacían que fuese realizada en meandro de arriba abajo y al revés, como es el caso de los códices de Oaxaca.

5 En la guarda posterior de la biblia hebraica se lee: «Esta brivia ebraica fue de fernando de lunar que fue secretario del Cabildo desta Sancta Yglesia de $t^{\circ}$ y Racionero y Capellan de los serenissimos rreyes...» PID: 0000188483 <http://bdh-rd.bne.es> (01/11/2016).

6 Se trata de una copia de 1329 de la obra Canon de Medicina de Abu 'Ali al-Husayn ibn Sina, conocido como Avicena. Nacido en Bujará en 980 y que fue una de las iluminarias de mundo medieval. <https://www.wdl.org/es/item/15440/view/1/1/> (01/11/2016). 
Otra diferencia significativa entre los códices europeos y los precolombinos radica en que los europeos están formados por una escritura logosilábica, es decir, basada en signos logográficos que designan palabras, sean fonéticos o alfabéticos. Mientras que la escritura de los pueblos mesoamericanos, que se encuentra en los códices precolombinos, emplea signos glifopictográficos, ideográficos y fonéticos. Así que gran parte de la escritura usada por estos pueblos puede considerarse como pictográfica, es decir, como pintura de objetos o acciones.
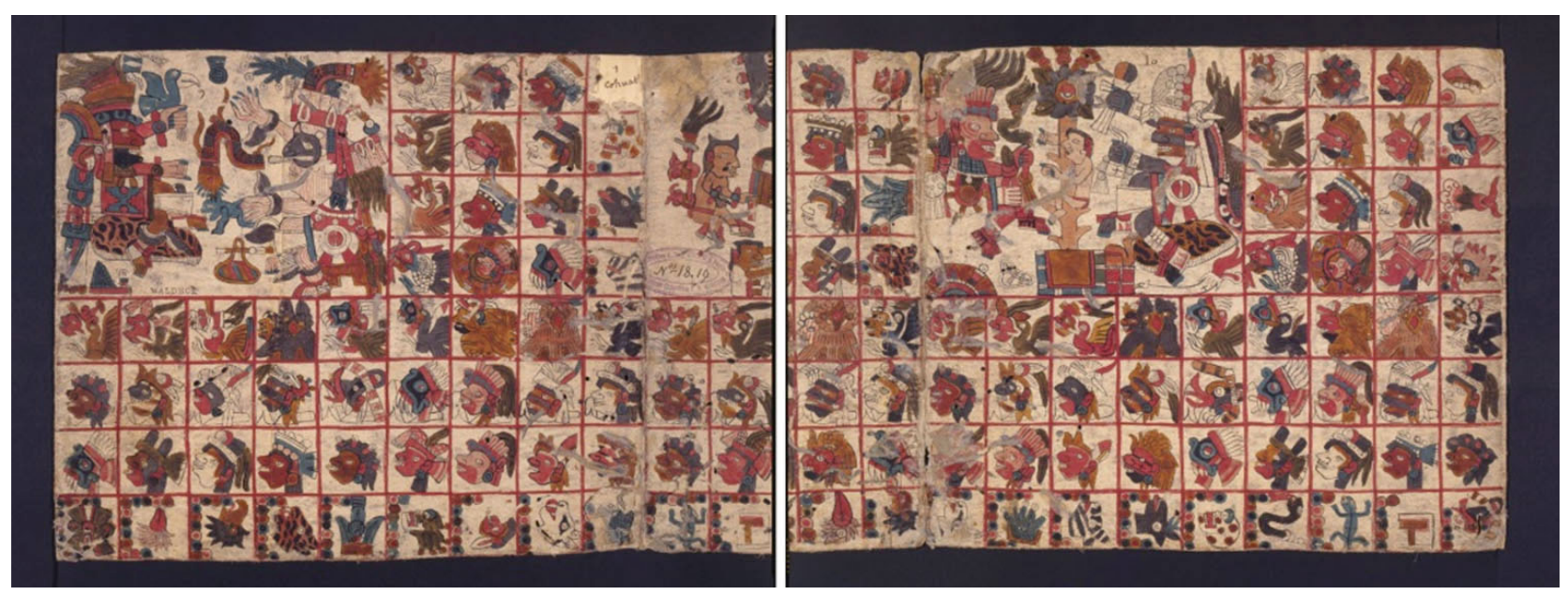

Fig.3. Códice pictórico Tonalámatl de Aubin, el cual se lee de arriba abajo y de derecha a izquierda. Instituto Nacional de Antropología e Historia de México?.

Como vemos los documentos eran escritos e ilustrados a mano, por lo que la invención en Europa de los tipos móviles supuso al mismo tiempo la invención de la tipografía. Además de permitir la reproducción seriada de un libro, los tipos o letras eran diseñados y reproducidos una y otra vez. Se materializa el libro como producto gráfico y se crea una nueva industria que mejorará las técnicas y procedimiento gráficos.

\section{CONTEXTO HISTÓRICO: LA IMPRENTA Y EL LIBRO}

En el momento en el que se sustituyen las tablas xilográficas por tipos móviles, Europa se encuentra en pleno Renacimiento, donde lo teológico convive con lo seglar a través de una filosofía humanista que se percibe en gran parte de las artes y las ciencias y, como no, el libro 'tipográfico' (Satué, 2010). Este cambio se verá culminado con una búsqueda de la llamada arquitectura gráfica, la composición y el diseño de tipografías. La imprenta será reconocida como un arte liberal que persigue una serie de beneficios sociales (Torné, 2012).

7 Se trata de un códice pictórico, que en un principio disponía de dos folios más que se perdieron. Los sacerdotes lo empleaban en rituales de adivinación. El códice dispone de un calendario religioso de 260 días. < https://www.wdl.org/es/item/15283/view/1/1/ > $(15 / 5 / 2016)$. 


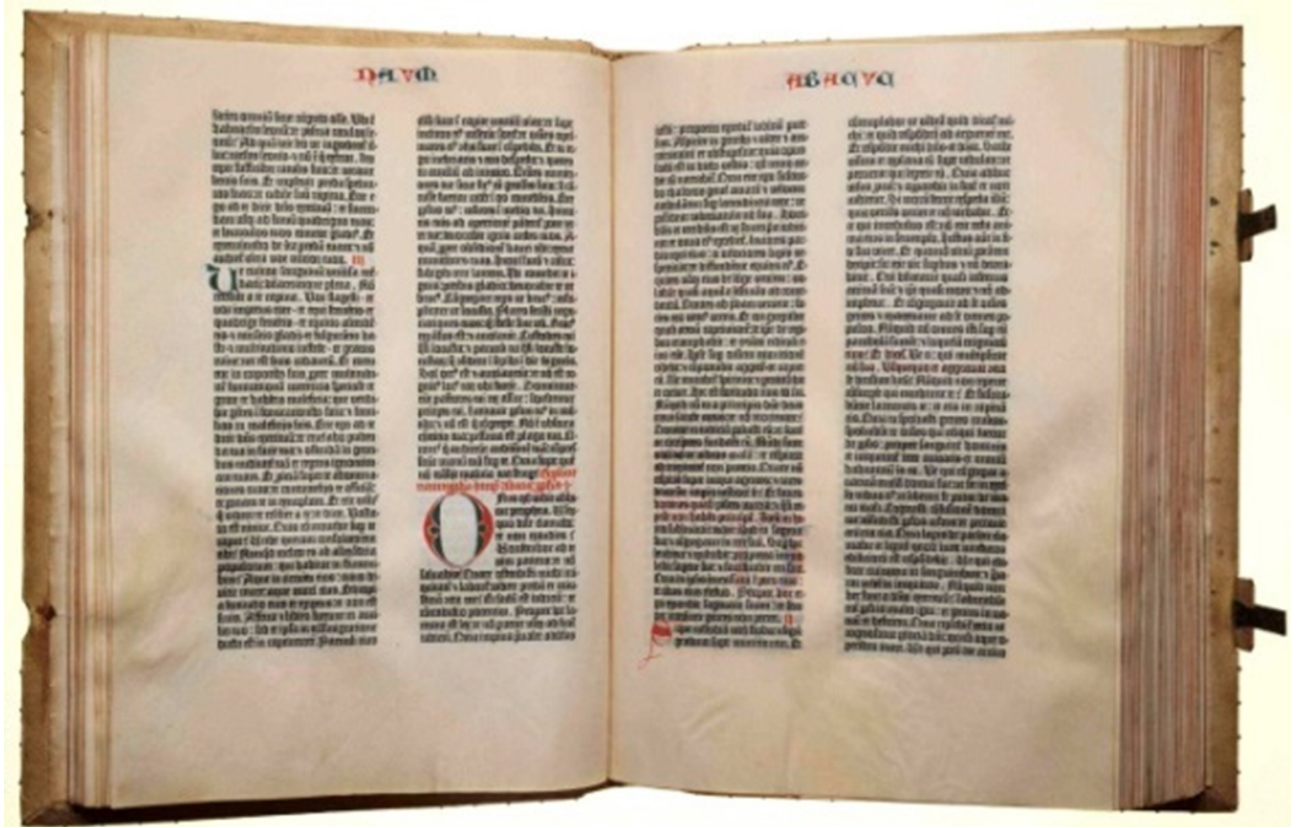

Fig. 4. Página de la Biblia de 42 líneas de Gutenberg (entre 1452-1455) ${ }^{8}$.

\subsection{LA TIPOGRAFÍA Y EL LIBRO EN OCCIDENTE}

Los primeros libros, impresos con tipos móviles, mantienen unas estructuras similares a los códices europeos, tanto en las ilustraciones como en la tipografía, imitando las fuentes góticas y manuscritas. Con el tiempo, los tipos de madera se sustituyeron por tipos de metal y se comenzaron a establecer convenciones y características propias, definiendo viñetas, signos de puntuación, orlas, así como la creación de tipos, formatos, etc. Las corporaciones y gremios de impresores, al igual que el arquitectónico, se ven influenciados por la geometría pitagórica, los sólidos platónicos, la proporción áurea, la aritmética, las relaciones armónicas y la arquitectura. Prueba de ello se aprecia en los principios codificados en los alfabetos diseñados por Luca Pacioli en 1509, basados, en su conceptualización, en la Divina proporción o proporción áurea, así como en el esquema de división de un libro basado en el mismo principio constructivo y en la proporción ternaria ${ }^{9}$.

En sendos casos se vislumbra nuevamente un intento de normalizar un proceso constructivo para la generación y diseño de fuentes o alfabetos; así como un proceso de división del espacio constructivo de las páginas del libro, para la posterior organización de los elementos que se insertarán. Lo que supone un avance en las disciplinas que más adelante denominaremos diseño gráfico editorial y tipográfico, como bases estructurales que serán aplicadas a fuentes tipográficas de todo tipo de lenguas. En este sentido cabe destacar la influencia

8 Se trata del primer gran libro impreso a partir de tipos móviles de metal, que se produjo en Mainz, Alemania. Su publicación supuso un punto de transición entre la Europa medieval y la moderna. Impresa en columnas dobles, las mayúsculas y los títulos fueron decorados a mano. Copia de la Biblioteca del Congreso. < https://www.wdl.org/es/item/7782/> (01/11/2016).

9 Tipos de proporciones: ÁUREA, llamada también divina proporción o regla de oro equivale a 1:1,618, esto es, si la anchura mide 1 la altura mide 1,618 (5/8); la proporción TERNARIA supone una media aritmética entre la áurea y la normalizada, equivale a la relación $1: 1,5(2 / 3)$ (Larrañaga, 1993). 
cultural, así se aprecia que los italianos tienden a recuperar formas alfabéticas del antiguo Imperio Romano, es el caso de Luca Pacioli o Nicolas Jenson ${ }^{10}$.

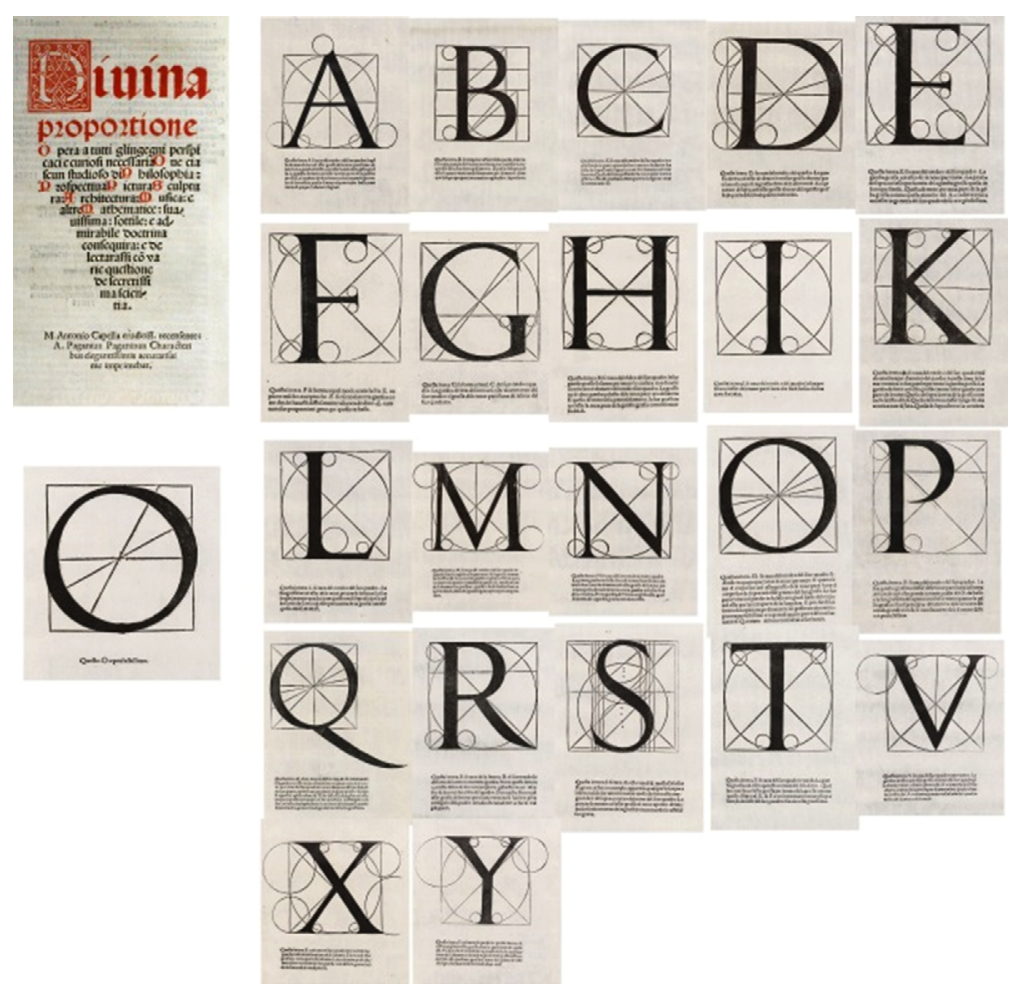

Fig. 5. Alfabeto diseñado por Luca Pacioli basado en la Regla de Oro o proporción áurea que se desarrolla en su obra De Divina Proporcione ${ }^{11}$, impresa en Milán durante la corte de Ludovico Sforza. Composición propia.

Este aspecto es relevante si se considera la forma como un signo transportador de significados culturales (Eco, 1988). En este sentido, la elección de esta forma de las letras, sustituyéndolas por las formas góticas medievales, implica incorporar a dichos diseños una serie de atributos vinculados a la época con reminiscencias del antiguo Imperio Romano y a la antigua Grecia. Muy en consonancia con lo que sucede en otras artes del Renacimiento. En este sentido la letra es portadora de su significado lingüístico además de una serie de atributos positivos que subyacen en su diseño humanista (Fig. 5).

Por otro lado, posteriores talladores de tipos (ingleses, franceses, entre otros) incorporan nuevos diseños, algunos de ellos profundizan en la estandarización como es el caso de Didot. Claude Garamond (1490-1561) tipógrafo, impresor y grabador, incorpora la cursiva versal o el concepto general de familia y serie. William Caslon (1692-1766) y John Baskerville (1706-1775) diseñan las históricas fuentes tipográficas que llevan

\footnotetext{
10 Grabador, tipógrafo, editor francés, se traslada a Venecia en 1470. Fue el creador de la letra de su mismo nombre, Jenson.

11 La obra incluye, además del desarrollo y construcción geométrica de las letras del alfabeto, una primera parte que define la sección áurea y los poliedros regulares, y una segunda parte en la que aplica la sección áurea en el cuerpo humano y arquitectura.

Composición propia realizada partiendo de imágenes obtenidas en varias fuentes. <https://www.metmuseum.org/art/collection/ search/336656> < https://ca.wikipedia.org/wiki/De divina proportione> (05/11/2016)

Estas proporciones también se aplicaron a la división de la página de un libro mediante el uso de la proporción áurea 1:1,5 y mediante el empleo de la división mediante el uso de la Divina Proporción Ternaria, 1:1,16.
} 
su nombre. Pierre Simon Furnier (1712-1768) fue el primero en racionalizar las medidas de los caracteres. En 1737 publicó su sistema del punto tipográfico. El ya mencionado Francisco Ambrosio Didot (1730-1804), hizo reformas y adaptaciones del punto tipográfico, llamándolo punto Didot, que se usa en la actualidad. Por último, nombrar a Giambattista Bodoni (1740-1813) y Robert Thorne (1794-1820) cuyas fuentes y diseños tipográficos han llegado hasta nuestros días.
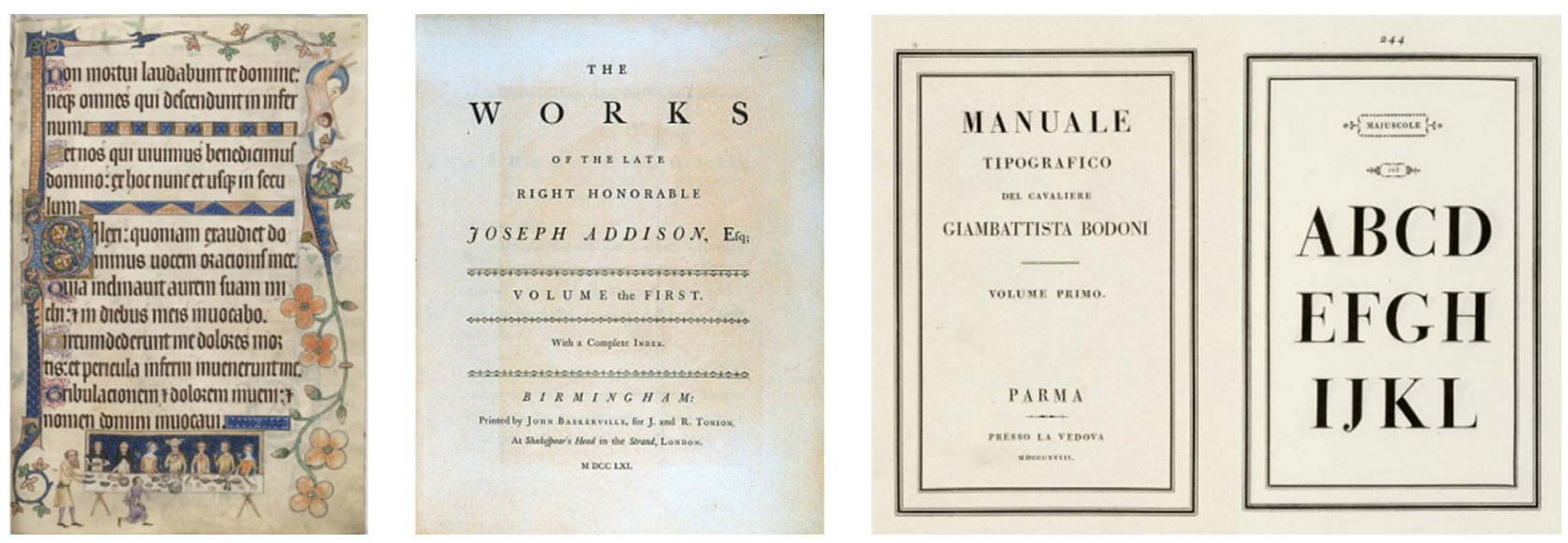

Fig. 6. En el cambio de diseño aplicado, entre la letra gótica (imagen izquierda) de los códices y las nuevas fuentes tipográficas (imagen central y derecha), subyace una evolución de concepto sustentado por una transformación social, económica y tecnológica ${ }^{12}$. Las fuentes de Caslon se consideran fuentes de transición.

Otro aspecto importante que cabe reseñar en la evolución constructiva de los signos pictográficos, aplicable a las lenguas europeas, es la herencia de las formas tipográficas en mayúscula y en minúscula, así como las cursivas. En su origen, la forma mayúscula es la más antigua de la escritura definida en el alfabeto fenicio, complementado por los griegos y trasmitido a todo occidente a través de los romanos.

En la codificación de carga comunicativa asociada hoy en día, los textos en mayúscula indican jerarquía, por ejemplo, para enfatizar nombres propios, titulares, resaltar frases, etc. Por su parte la escritura en minúsculas surge como resultado de la escritura petroglifos, en la que las formas se van estirando por la dificultad de escribir sobre piedra. Se usa ampliamente en el siglo VIII en los reinos de Carlo Magno. Esta forma de escritura estará presente en los nuevos libros impresos, y es la forma estándar para los contenidos. Por otro lado, la forma cursiva creada por el impresor Aldo Manucio en 1501, es una derivación de la empleada por las cancillerías romanas. En la actualidad se asocia su aplicación a la señalización de frases, o textos específicos (Larrañaga, 1993).

\footnotetext{
12 Página del salterio 'The Luttrell Psalter', creado en 1325-40. Se trata de un manuscrito profusamente ilustrado con ricas y delicadas imágenes que describen la vida cotidiana. Las imágenes en muchos casos animadas muestran el el trabajo y el juego durante un año en la propiedad de Sir Georffrey's. < https://www.bl.uk/collection-items/the-luttrell-psalter>

Manual tipográfico publicado en 1818, publicado después de su muerte, que recoge las fuentes tipográficas diseñadas por Bodoni. < https://en.wikipedia.org/wiki/Bodoni\#/media/File:Manuale-Tipografico1.jpg>

Tipos Baskerville en la reproducción de la obra de Addison, impresa en $1761<$ https://es.wikipedia.org/wiki/John_Baskerville\#/media/ File:Work-baskerville.jpg > (05/11/2016)
} 

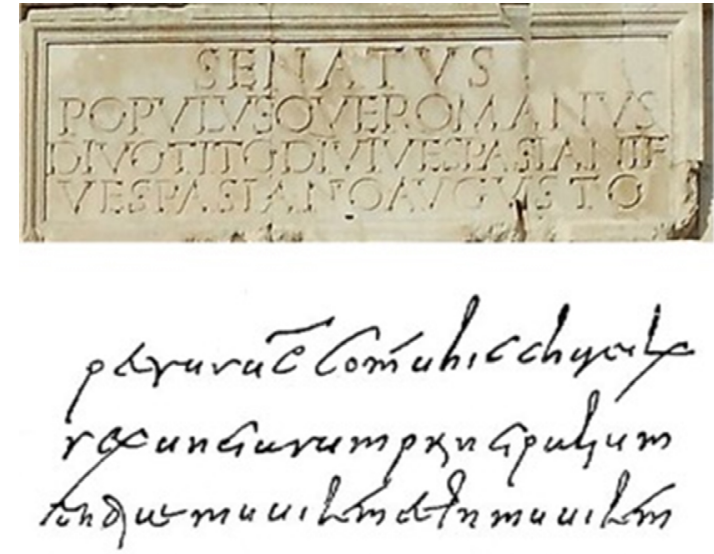

12. Minuscola corsiva, sec. VII in. - Docemento di Raveana. IManchester, Jahn Ryiands Libr., Ms. lat. I: Papiro Marini XC). Petrus vir elarissinus connet thic chartule... sex encierum principoliem...
subj]luntiae murvilem et innuvilem...

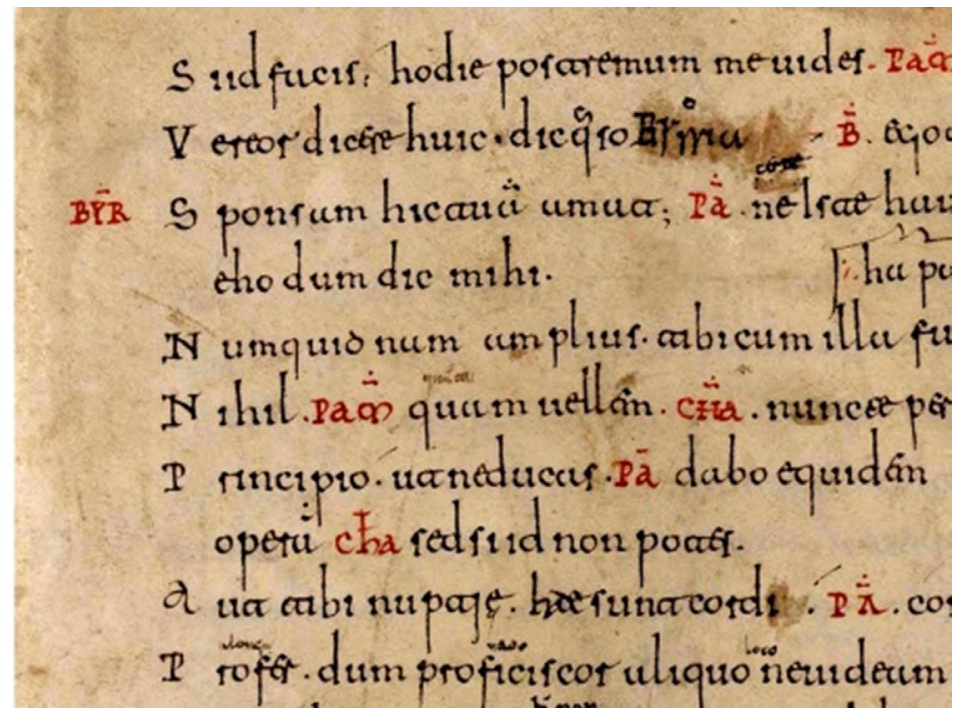

Fig. 7. Izquierda: ejemplo mayúsculas, estilo Romano, inscripción en Arco de Tito ${ }^{13}$. Derecha: ejemplo de minúscula en estilo carolina, extraído del manuscrito de Terencio del siglo $\mathrm{XI}^{14}$. Inferior izquierda: ejemplo de escritura cursiva de estilo cancilleresco del extraído de Documento del siglo VII ${ }^{15}$. Composición propia.

Podemos decir que el libro impreso en la Edad Moderna está constituido por los siguientes aspectos:

- Una amplia paleta tipográfica basada en tipos romanos (o redondos) y cursivos (o itálicos).

- Control de interlineados.

- Uso de registros versales (o mayúsculas), versalitas y minúsculas (en el tipo romano se hacían los tres y en los tipos cursivos solamente se usaban los versales y las minúsculas).

- Una gama de cuerpos suficientemente amplia.

- Diseño de fuentes basados en la Divina proporción.

- Diseños de páginas basados en la Divina proporción o proporción ternaria.

- Habitualmente uso de dos tintas, la negra y la roja.

- Perfecta justificación de los párrafos.

- Portada.

Todo ello en su conjunto aporta al libro de la Edad Moderna claridad, luminosidad y legibilidad, además de mostrar una impresión nítida en sus páginas y portadas.

\footnotetext{
13 Inscripción que aparece en la parte superior del Arco de Tito, alrededor del año 81. Se trata de un ejemplo claro de mayúsculas estilo Romano. <https://es.wikipedia.org/wiki/Mayúsculas_cuadradas_romanas\#/media/File:Arch.of.Titus-Inscription.jpg>

14 Fragmento del folio $5 \mathrm{r}$ del manuscrito de Terencio del siglo XI, del monasterio de San Millán de la Cogolla, se encuentra en la actualidad en la Biblioteca Nacional de España. El manuscrito recopila las comedias de Terencio. <https://es.wikipedia.org/wiki/Terencio\#/ media/File:Comedias_de_Terencio_s_XI_f5r.jpg> (05/11/2016)

15 Las versiones de escritura cursiva cancilleresca surgen durante los siglos II y II d.C., la cual desaparecerá al ser sustituida por la escritura carolingia. <http://conscriptio.blogspot.com.es/2013/01/la-escritura-romana.html> (05/11/2016)
} 


\subsection{EL INCUNABLE Y EL LIBRO DE BOLSILLO, PRIMER PRODUCTO MODERNO CON MARCA}

En este contexto del siglo XV, donde las marcas de gremios y de corporaciones están ampliamente sistematizadas, la aparición de los incunables, aproximadamente en el año 1500, supone el primer producto moderno con marca y datos de producción. Contiene de manera normalizada la fecha en la portada o en el colofón ${ }^{16}$, el pie de imprenta de libro donde consta el editor con su marca de impresor ${ }^{17}$, el tipógrafo, la ciudad y el año o años de edición, así como la propia portada (Fig. 8). Así vemos que estos productos modernos constaban de un gran número de datos haciendo referencia a la zona de producción, año, así como nombre del editor, entre otros.

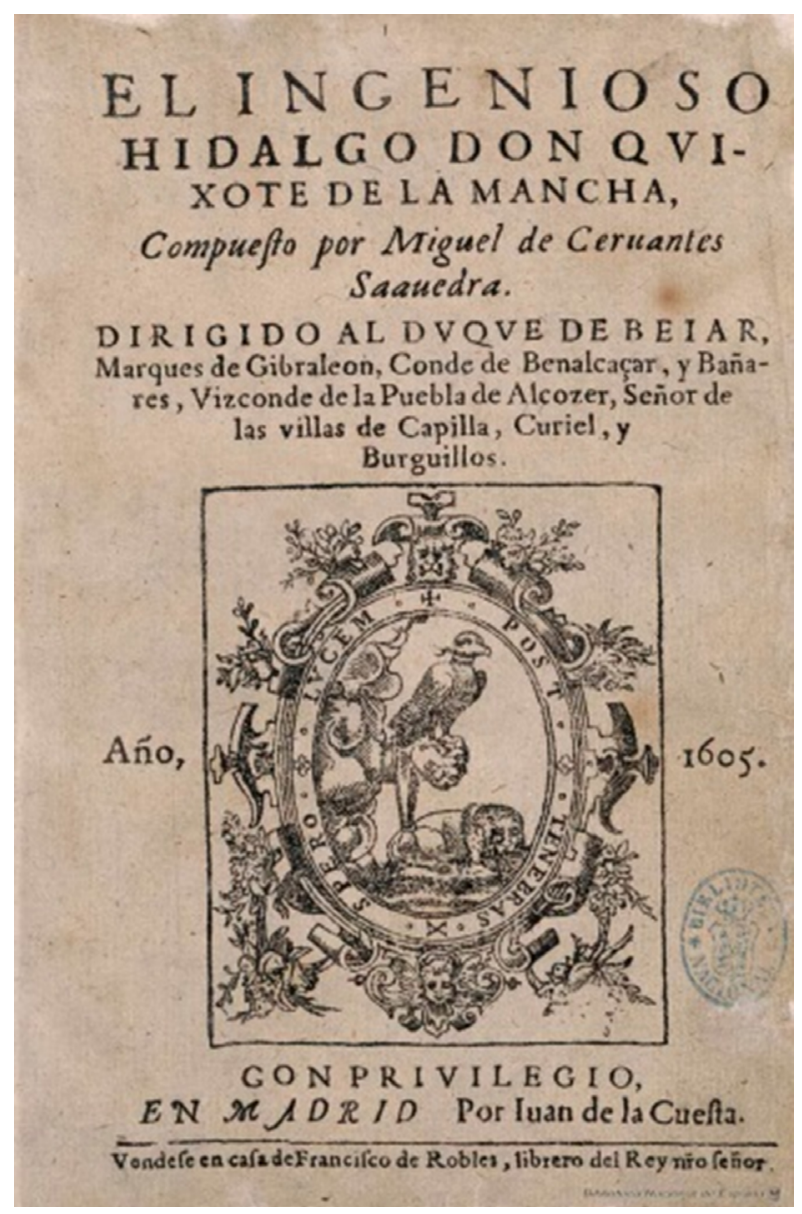

Fig. 8. Miguel de Cervantes, El ingenioso hidalgo Don Quixote de la Mancha, Madrid: Juan de la Cuesta, 1605, 4º. Biblioteca Nacional de España ${ }^{18}$.

17 Las marcas de impresor, también llamadas marcas tipográficas, son empleadas en la época de la impresión tipográfica inicial y siguen las convenciones emblemáticas anteriormente desarrolladas.

18 El Ingenioso Hidalgo Don Quixote de la Mancha compuesto por Miguel de Cervuantes Saauedra; dirigido al Duque de Beiar, Marques de Gibraleon, Conde de Benalcaçar y Bañares, Vizconde de la Puebla de Alcozer, Señor de las villas de Capilla, Curiel y Burguillos. Cervantes Saavedra, Miguel de 1547-1616 — 1605. CERV/000118 < http://bdh-rd.bne.es/viewer.vm?id=0000042946> $(07 / 11 / 2016)$ 
Por otro lado, uno de los exponentes en la fabricación de libros modernos fue el impresor veneciano Aldo Manuncio (1449-1515), que además de diseñar la tipografía cursiva moderna, produce, en cierto modo, un concepto nuevo de producto editorial: el libro de bolsillo (tal como lo define Enric Satué). Éste surge como consecuencia de factores económicos y sociales que determinan la necesidad de un producto que sea posible llevar en el bolsillo para proceder a su lectura 'en cualquier lugar'. En el siglo XV estos libros, que son fáciles de llevar, de leer y de manejar, también son más baratos y representan una verdadera revolución como producto editorial (Torné, 2012).

Emilio Torné en "Arquitectura tipográfica" nos dice:

«En el siglo XVI no se asiste tan solo a una natural evolución libraría en el tiempo (con sus transformaciones de géneros, usos, públicos...), sino también a las consecuencias de un cambio radical en las prácticas de escritura. De este proceso resulta que para mediados de dicho siglo el libro impreso ha encontrado ya una identidad propia en sus formas: en sus caracteres, en su composición, en su compaginación, en su figura, en sus formatos...»

Como vemos, en este sentido, el libro es doblemente el exponente de producto moderno. Pues se tienen en cuenta los beneficios funcionales del producto, e incluso, los beneficios emocionales de sus consumidores, en los términos modernos expresados por Aaker (2002, p. 100), aun considerando que el marketing no aparece hasta varios siglos después.

Aldo Manuncio también es innovador en la formulación y diseño de su marca de impresor, que en términos actuales sería la marca de la editorial, con todo lo que conlleva. Recordemos que en este periodo todavía las corporaciones, gremios y maestros definen sus marcas de impresor ${ }^{19}$ bajo convenciones emblemáticas, por lo que contiene mayoritariamente, una parte gráfica o picturae (emplematizada) y un lema que cumple con los preceptos marcados: versos latinos o en latín o motes, como el ejemplo de la marca de impresor de Bartolomeo Sermartelli que aparece en la Fig. 9 izquierda. Si la comparamos con el diseño innovador de la marca de Aldo Manuncio, que se sirve de elementos simbólicos extraídos de obras clásicas o cultura romana, vemos que muestra un claro ejemplo transformador, en cuanto a concepto, orientando los elementos simbólicos hacia «un enfoque que recoge elementos y símbolos de la antigüedad romana» (López, 2006). Así vemos que Aldo utiliza tres elementos: el delfín, el áncora y un círculo. Se trata de una marca de impresor que aparece en las obras de Manuncio a partir de 1502, en concreto a partir de su obra Poetae christiani veretes. Es un símbolo compuesto que estaba insertado en las monedas romanas de la época de Tito y Domiciano, aquí recogemos una muestra en la representación de la moneda de Tito Vespasiano (80 d.C.). Algunos estudiosos indican que Aldus decidió hacerla su marca tras leer uno de los pasajes de la obra que imprimió Hypnerotomachia Poliphili (impresa en el año 1499 en Venecia), en el pasaje del capítulo VII, Polyphito sale del laberinto (algunos lo denominan 'amor animal') y en un paraje, ya en la región de los Cinco Sentidos y del

19 También son llamadas 'divisas de impresor' o 'marcas tipográficas', comenzaron a diseñarse con unas simples siglas o con un anagrama del nombre de impresor, que con el tiempo comenzaron a dotar de carga simbólica e incluir lemas que hacía referencia a su vida o a su producción. En ocasiones varios impresores empleaban la misma marca lo que supuso que en 1539 Francisco I prohibiese esta práctica con el fin de diferenciar las marcas de cada impresor y, en consecuencia, su producción. 
Libre Albedrío, se encuentra con un antiquísimo puente que contiene en sus pretiles unos jeroglíficos, entre los que se encuentran un ancla, un círculo y un delfín enroscado en una caña. Poliphilo interpreta el mensaje y lo traduce como 'sempre festina tarde' (apresúrate siempre despacio) ${ }^{20}$.

En relación al lema, Erasmo comenta cómo Manuncio le indicó que:

«el lema es digno de ser grabado en todas las columnas y escrito con letras de oro en las puertas de los templos, y explica que por eso está pintado en las salas de los magnates y lo llevan los caballeros en sus anillos y los reyes en su cetro» (citado por López, 2006).
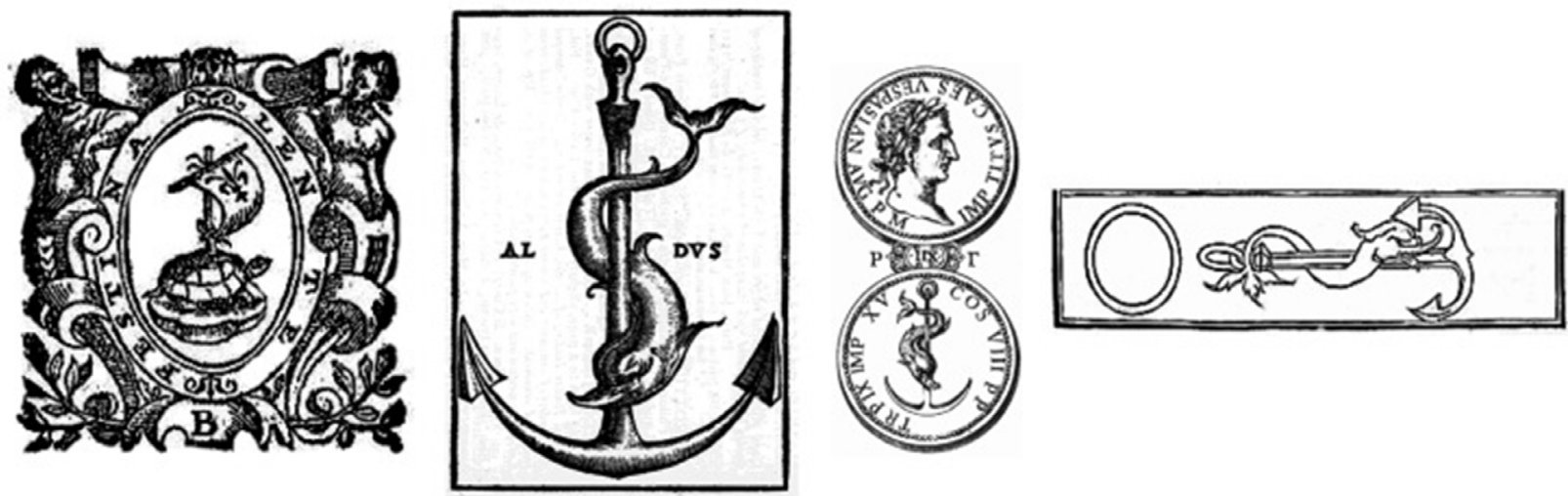

Fig. 9. Izquierda: Marca de impresor de Bartolomeo Sermartelli emblematizada. Derecha: marca de impresor veneciano Aldo Manuncio junto a detalles de símbolos y procedencia ${ }^{21}$

Aun cuando la marca posee características emblemáticas como el uso de lema (aunque no visible), se aprecia un cambio en el enfoque, ya que posee un carácter simbólico que nos remite a los conocimientos griegos y romanos, al tiempo que excluye elementos ornamentales como los tenantes. Manuncio sintetiza el lema en los propios elementos gráficos: el círculo significa sempre, el delfín festina y el ancla tarde. Por lo que el resultado es un diseño conceptualmente innovador aun siguiendo el proceso simbólico del diseño al uso. Con toda probabilidad, es por ello que se trata de una marca que ha perdurado hasta el siglo XX (Colección Áncora y Delfín de la editorial española).

\subsection{LA PORTADA, SISTEMAS TIPOGRÁFICOS DE MARCAS DE DISCURSO Y OTROS ELEMENTOS}

Con el avance de la tipografía, como impresión mecanizada a través de la prensa mediante tipos móviles, va tomando forma el acto de la composición. De tal manera que se inician en el control de los espacios entre letras, entre palabras y entre líneas, y a definir una perfecta justificación entre los párrafos. Este proceso

20 Existen más alusiones al origen de los elementos simbólicos detalladas en el estudio de Los libros de Emblemas y la imprenta de Sagrario López.

21 Extraídas de Los libros de Emblemas y la imprenta de Sagrario López. 
resulta un tanto lento en su implantación, ya que inicialmente muchos incunables imitan levemente las irregularidades de los códices.

Hay que recordar que los códices no poseen portadas, ni presentan una estructura, ni poseen divisiones. Además, las palabras aparecen seguidas sin espaciado entre las mismas, lo que dificultaba su lecturabilidad y legibilidad. Así, el uso de una retícula o división de la página empleando la proporción áurea, junto con una serie de reglas compositivas, y una lógica evolución de la inserción de la imprenta formalizó el libro moderno. Los talleres, al plantear criterios ortotipográficos, crearon reglas de ortografía y puntuación para las lenguas vernáculas, siendo distinto en cada país o región, aun hablando de un producto y producción que hoy consideramos como globalizado.

Como subraya Torné (2012, p.87):

«Se trata, en efecto, de designar el sistema, más amplio que el de la puntuación, lentamente desarrollado por la tipografía. Se suele decir que los tipógrafos fijaron la ortografía; se ignora que elaboraron un sistema puramente tipográfico de marcas de discurso» (citado por Laufer, 1982)

En los siglos XVI, XVII y XVIII se normalizan o convencionalizan aspectos compositivos, usos de estilo y paratextos como:

- En el uso de la sangría, los tipos de párrafos o en los índices.

- En los procedimientos de anotación de los libros: marginales, finales y al pie.

- En la numeración y división de las páginas.

- En los criterios tipográficos que se definen para la segmentación en capítulos y apartados.

- En la distribución de funciones que se definen para el uso de las versales, las redondas y las cursivas.

- Elementos preliminares como dedicatoria, textos poéticos, etc.

- Preliminares legales como el privilegio, la aprobación, la tasa, etc.

- Incorporación de un prólogo.

- La inclusión de índices y tablas.

Por lo que respecta a la portada, resulta interesante destacar que la definición de portada como la detalla Covadonga ${ }^{22}$ en sus acepciones 1. Portada. 2. Portal. 3. Portero, vide puerta. Buena portada de persona, buena presencia. Correa (1627), por su parte, en su libro de refranes recoge la frase 'Todo es portada' de la que comenta: «Dícese cuando no hay más de buenas apariencias». En este periodo la portada, que nace, como hemos indicado en el siglo anterior en los incunables, busca su propia definición en el sentido comercial.

En este periodo la portada recoge los datos sustanciales: el título, el autor, la persona a quien se dedica, el 
lugar, el año, el impresor, el editor... y en algunas construcciones arquitectónicas, aunque predomina el diseño textual.

Esto es así porque a nivel de diseño, la portada es un elemento con parámetros específicos y aunque el carácter netamente comercial y publicitario del producto-contenido (publicitando el contenido a través de la información gráfica y escrita que aparece en la portada) no tiene lugar hasta siglos más tarde, es evidente que en palabras de Torné (2012): «los diferentes usos y prácticas de lectura son principalísimo agente de cambio en la historia del libro», llegando a indicar los factores que definen su variabilidad en el tiempo, como son:

- Factores literarios.

- Factores editoriales y comerciales.

- Factores legales.

- Factores estéticos (pues el libro como producto de consumo comparte los cambios del gusto que se producen a través del tiempo).

- Factores relacionados con la lectura (los diferentes usos y prácticas de lectura son principalísimo agente de cambio en la historia del libro).

Los dos últimos factores son evidentes en el planteamiento comunicativo del diseño en general y, más específicamente, del diseño de libros como producto en particular; derivando en libros de viaje, libros infantiles, técnicos, didácticos de arte... y llegando a tener en nuestros días unas especificaciones constructivascomunicativas y lingüísticas-constructivas bien distintas (Moles y Janiszewski, 1990) donde lo textual y lo gráfico conviven.

En este sentido el libro sufre un proceso significativo, ya que, de un predominio de lo textual, como se observa en los fabricados durante el siglo XV deriva, en nuestros días, a un enfoque donde conviven lo textual con lo gráfico. Igualmente se observa una evolución que transcurre desde una primacía de la geometría sobre la gramática y de lo visual sobre lo semántico. Como vemos, existe una primacía de lo auditivo frente a lo gráfico, que para Ong (2006) se debe a un proceso evolutivo y de cambio en el individuo y las sociedades.

\subsection{GLOBALIZACIÓN DEL LIBRO MODERNO}

Dado que estamos tratando el proceso de globalización del libro hacemos un inciso para incorporar como los avances técnicos, en este sentido, la prensa de impresión tipográfica, abordó no solamente el acercamiento de un producto, el libro, a un mayor número de personas, sino como su inserción profesional en diferentes puntos del globo permitió extender el producto más allá de los límites iniciales de Maguncia en 1457, así como su adaptación en los diferentes países mediante su ajuste en el contenido expresado en las lenguas vernáculas correspondientes, además de ajustes estilísticos en cada periodo.

Veamos un recopilatorio extraído del libro de Borao (1860) que nos da buena cuenta del proceso de introducción de este producto en distintos países del mundo a través de la aparición de imprentas en el país o ciudad específica. Los datos que recoge van desde el año 1457 hasta el año 1817, como vemos un proceso arduo y lento si lo comparamos con las tecnologías actuales. La lista es la siguiente: 


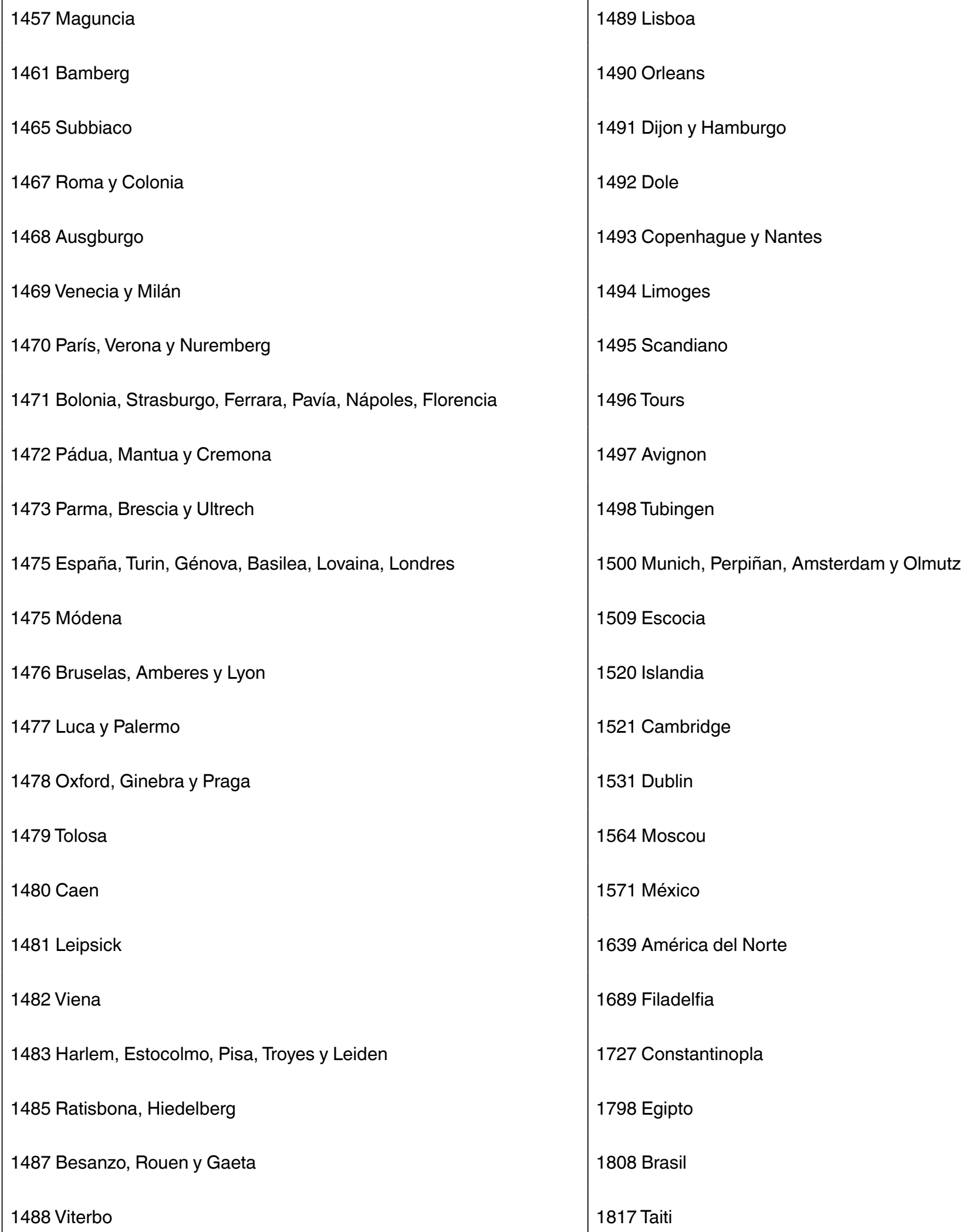

Hay que reseñar que mayoritariamente se refiere a libros impresos en caracteres latinos. 


\subsection{TRADUCCIONES DE LIBROS COMO EJE DE LA GLOBALIZACIÓN MODERNA}

Con mucha probabilidad los países que fueron incorporando la impresión por tipos fueron incluyendo matrices de tipos en diferentes caracteres, por ejemplo, el cirílico. En este sentido no nos vamos a expresar, pero si es relevante para el estudio entender que, en muchos casos, la traducción de obras maestras fue y es un sistema habitual de introducción de un producto en nuevos mercados. Así, por ejemplo, en 1538 el humanista francés Guillaume Postel, que había formado parte de la embajada enviada por el rey Francisco I a Constantinopla, publicó Grammaire arabe (gramática árabe) en París, la primera que se imprimía. Tenemos los casos del chino Xu Guangqi, que en 1607 se encargó de la traducción de los seis primeros libros de los Elementos de Euclides junto con Matteo Ricci (Cornejo, 2012).

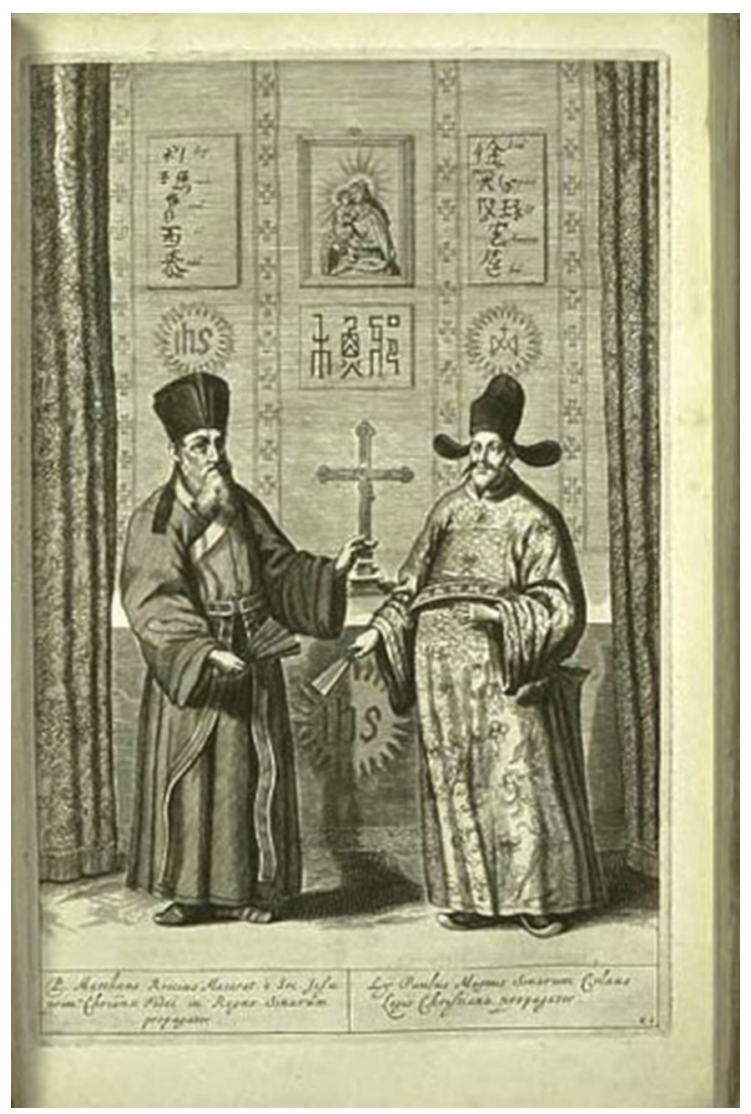

Fig. 10. Matteo Ricci, SJ, and Xu Guangqi from Athanasius Kircher's China Illustrata (Amsterdam, 1667) ${ }^{23}$.

Igualmente indicar que en estos siglos son mayoritariamente los misioneros jesuitas, dominicos y franciscanos los que se encargan de introducir libros en otros países. Como es el caso del misionero jesuita Alexandro Valignano (1539-1606) que construyó misiones permanentes en Asia Oriental y fue nombrado visitador de todas las misiones establecidas desde Mozambique hasta Japón en 1573. Valignano fue el primer jesuita

23 El jesuita Ricci (1552-1667) es conocido como el fundador de la labor misionera en China. A la derecha Xu Guangqi (1562-1633) fue miembro de la dinastía Ming en Shanghái y converso influyente al cristianismo. <https://www.mtholyoke.edu/courses/rschwart/hist151f08/lectures/ricci_images.htm> (15/11/2016). 
que propuso el aprendizaje de las lenguas locales, el respeto y la asimilación de la cultura y la adaptación del mensaje cristiano, aunque su aplicación se llevó a cabo de manera muy desigual. Aun así, como concepto, resulta muy moderno ya que persigue lo que en su época llamaron la acomodación ${ }^{24} \mathrm{o}$ inculcación. El máximo exponente de este proceso es la primera edición del Tianzhu shiyi o Catecismo de Matteo Ricci de 1603.

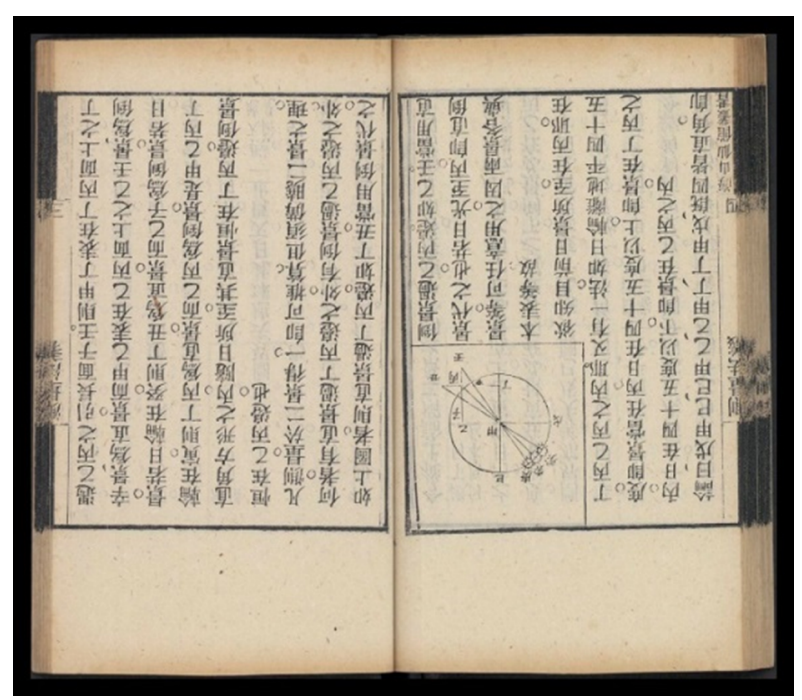

Fig. 11. Ce liang fa yi (Obra sobre trigonometría) de Matteo Ricci25.

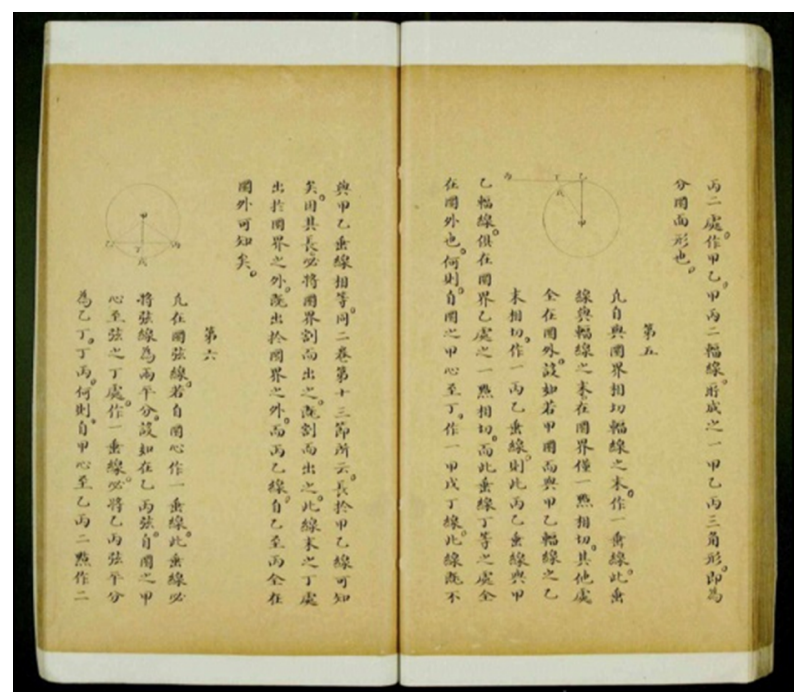

Fig. 12. Se trata de una copia manuscrita muy rara del Ji he yuan ben (Los elementos de geometría) de los jesuitas Zhang Cheng (Jean François Gerbillon, 1654-1707) y Bai Jin (Joachim Bouvet, 1656-1730) ${ }^{26}$.

24 Se trata de un intento de mostrar a los intelectuales chinos que el cristianismo no se opone al confucionismo.

25 Tratado sobre trigonometría de Li Madou, nombre chino del jesuita italiano Matteo Ricci (1552-1610). <https://www.wdl.org/es/ item/11436/ > (15/11/2016).

26 El emperador Kangxi en 1690, convocó a los misioneros franceses, Zhang Cheng (Jean François Gerbillon, 1654-1707) y Bai Jin (Joachim Bouvet, 1656-1730) para que le enseñaran matemáticas. Al considerar la obra de Ricci muy compleja al nivel de traducción decidieron realizar este manuscrito que posee correcciones del emperador. Podría tratarse de un borrador preliminar ya que se trata de un manuscrito y no de un libro impreso con tipos. < https://www.wdl.org/es/item/7103/\#q="Matteo+Ricci\%2C+SJ+y+Xu+Guangqi+de+China+> (15/11/2016). 
Cabe indicar, como señala Clara Revuelta (2014, p. 38) que "la labor evangelizadora de los pueblos de 'Ultramar', no puede ser considerada como un hecho desconectado del movimiento traductor que se produce en la Europa cristiana (católica o protestante) a lo largo del siglo XVI con el desarrollo del Renacimiento". Este hecho viene constatado por las numerosas ediciones políglotas de la Biblia, en versiones traducidas al caldeo, hebreo, arameo, siriaco, etiópico, persa, arábigo, griego y latín. Esto se debe a que comienzan a tener importancia científico-cultural con la impresión de la Biblia Políglota Complutense (1514-1517).

La inserción de varios idiomas nos remite al uso moderno de querer clarificar y comunicar un mismo contenido a varios grupos culturalmente o lingüísticamente distintos. Un concepto que podemos apreciar en todo tipo de diseños gráficos. También identificado como un producto global, ya que se incorporan en una misma pieza los elementos diferenciadores que permiten que el libro sea adquirido por lectores con características sociales, culturales y lingüísticas bien distintas. En este sentido, la biblia políglota impresa es el primer producto moderno globalizado pues aúna todos los elementos que constituyen este concepto.
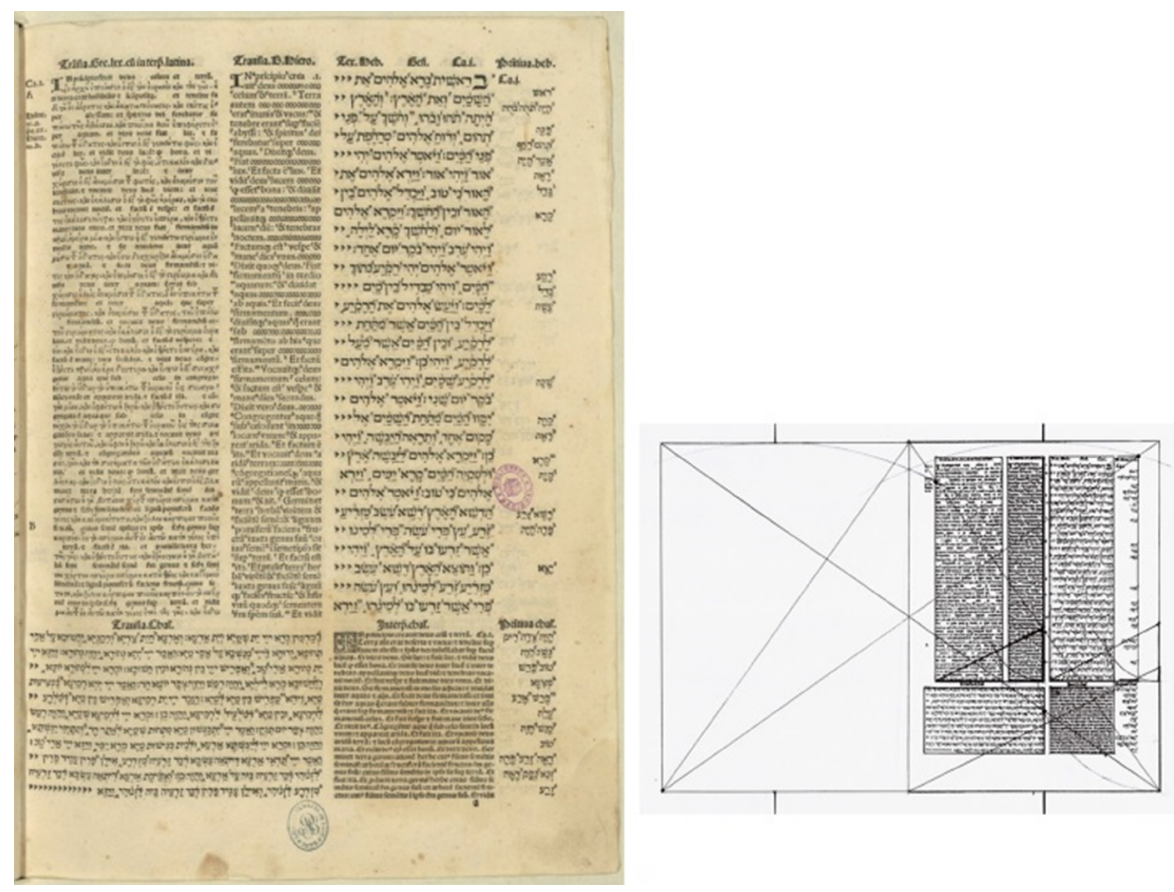

Fig. 13. Biblia Políglota Complutense (Alcalá, 1514-1517) ${ }^{27}$ y esquema constructivo de la Biblia Polígota ${ }^{28}$.

Es interesante destacar la inserción de fuentes no latinas, claro ejemplo de expansión y acomodación a la realidad global, en la que coexisten lenguas latinas, cirílicas, persas, chinas, etc. que conforman un grupo de saber mayor.

27 La Biblia políglota complutense es la primera edición impresa de la Biblia completa. Se trata de un proyecto que fue concebido por Francisco Jiménez Cisneros (1436-1517) cuando proyecto la rehabilitación de la antigua Universidad Alcalá de Henares. <https://www. wdl.org/es/item/10636/\#q=biblia+pol\%C3\%ADglota\&qla=es > (17/11/2016).

28 Imagen extraída del estudio de Anna Muntada Torrellas, "Del Misal Rico de Cisneros y de la Biblia Políglota Complutense o bien del manuscrito al impreso". Departament d'Art Universitat Autònoma de Barcelona. 
Por otro lado, en el contexto cultural occidental actual, las cualidades gráficas de la grafía han adquirido un verdadero valor comunicativo, ya que a la forma gráfica se asocian atributos y valores concretos, como fortaleza, debilidad, elegancia, etc. Creando de este modo un verdadero lenguaje, que permite seleccionar las formas tipográficas en el diseño, para una adecuada comunicación debido a los valores connotativos de las letras (Moles y Janiszewski, 1990), así como el ajuste estético derivado de modas culturales. Esto es un hecho evidente que se constata con la propia evolución y suma de los diseños tipográficos que se han ido incorporando desde el siglo $\mathrm{XV}$ hasta nuestros días, y que se agregan a tendencias o movimientos artísticos o hitos de referencia en el mundo del diseño.

\subsection{CONSTANCIA HISTÓRICA DE TIPOGRAFÍAS NO LATINAS EN EUROPA}

Resulta interesante destacar que, aunque desde el siglo XVI se han realizado traducciones (en libros), no solamente por parte de los misioneros, sino también por tipógrafos europeos como Nicholas Jenson, son pocos los datos referenciados de tipografías orientales que hayan sido diseñadas.
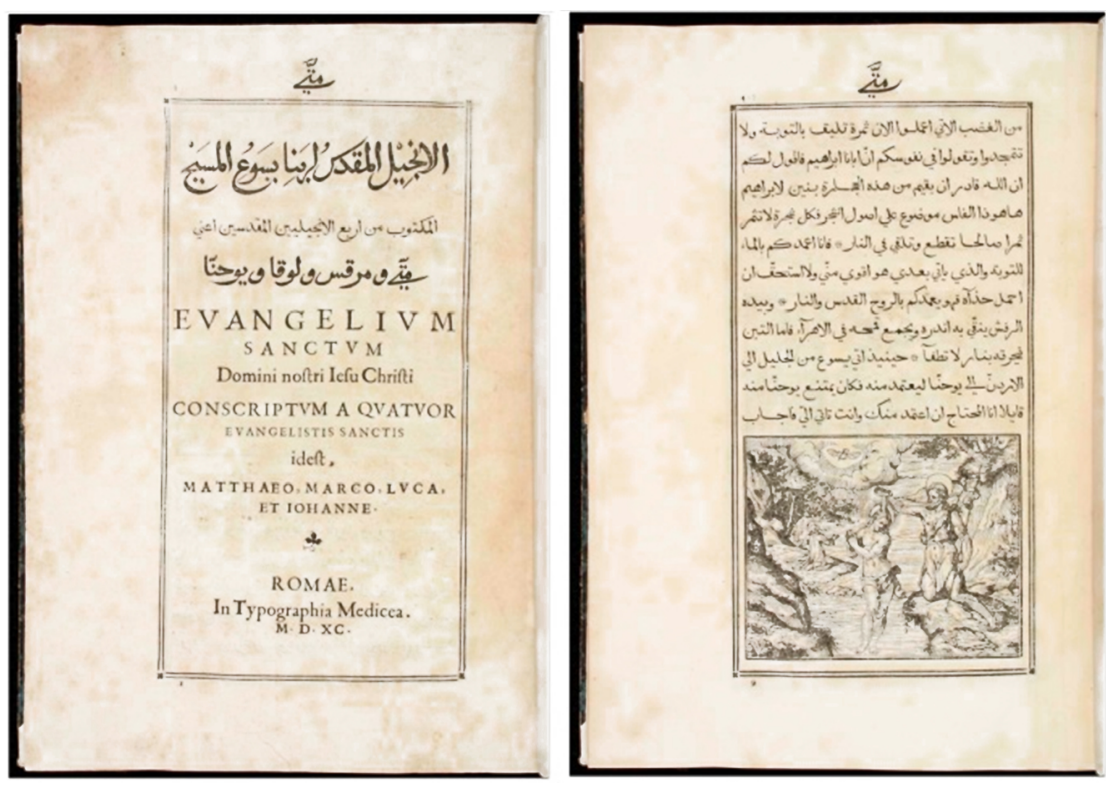

Fig.14. Evangelio en árabe impreso en La Typographia Medicea entre 1590 y 1591. La tipografía árabe cursiva fue diseñada por Robert Granjon (1513-1590), quien representa uno de los intentos de tipógrafos europeos de crear tipografías de letra árabe ${ }^{29}$.

Así por ejemplo, ha quedado constancia de que los caracteres árabes aparecen por primera vez impresos en un libro en 1486, cuando Martin Roth (sacerdote dominico) encarga a la imprenta de Erhard Reuwich en Maguncia, la impresión de la famosa crónica del "Viaje y Peregrinación de Ultramar al Santo Sepulcro de la Ciudad Santa de Jerusalén”, hecha y compuesta en latín por Bernard de Breydenbach; el grabador y tipógrafo 
Nicholas Jenson (Francia, 1420-Venecia, 1480) del que ha quedado constancia que realizó la impresión del Nuevo Testamento en árabe; el tipógrafo Robert Granjon (1513-1590), diseñó tipografías de letra árabe, de las cuales ha quedado constancia en varias publicaciones; el impresor y tipógrafo Giambattista Bodoni (Saluzzo, Italia, 1740 - Parma, 1813) que realizó la edición de la Oratio dominica publicada en 1806, como recordatorio del viaje realizado por el Papa Pío VII a París para asistir a la coronación de Napoleón Bonaparte. Esta obra contiene un prólogo en francés, italiano y latín y contiene la traducción a 155 lenguas del Padre Nuestro. De hecho, se trata de un maravilloso catálogo de alfabetos y de caracteres tipográficos.

A principios del siglo XVII había aparecido en Francia una tipografía oriental, caracteres árabes que habían sido diseñados por los libaneses del Colegio Maronita de Roma ${ }^{30}$. Por otro lado, nos ha quedado constancia la imprenta oriental de los Médici (La Typographia Medicea) que fue fundada en 1584 por el cardenal Fernando de Médici, en la que fueron impresas obras religiosas en árabe, sirio y turco. También ha quedado constancia de la Imprenta en lenguas orientales, instalada en París en el siglo XVII por el diplomático francés François Savary de Brèves. Éste llevo consigo a Francia los caracteres árabes diseñados en Roma por los libaneses del Colegio Maronita de Roma.

\section{CONCLUSIÓN}

A lo largo de este recorrido histórico se observa que la incorporación del libro facilitó la transferencia de conocimiento, basada en un sistema de impresión mecanizado; que hizo evolucionar el propio producto bajo una demanda de lectura, la cual extendió su uso a espacios públicos. Sería el llamado libro de bolsillo.

Igualmente generó un sistema constructivo que permitió estandarizar su estructura interna y fabricación, mediante el diseño de fuentes tipográficas basadas en tamaños, estilos, familias, etc. En los siglos que el estudio ha abarcado también se aprecia un proceso de normalización, donde se convencionalizan aspectos compositivos como el empleo y definición de sangrías, párrafos, finales y pies, numeración de páginas, prólogos, índices y tablas, así como la portada y la inserción de la marca de impresor.

Por otro lado, se aprecia que el cambio de códices a libros supuso transitar de un sistema en el que convivían lo gráfico con lo textual, a un sistema textual mayoritariamente durante la Edad Moderna.

Por otro lado, se observa que la evolución del libro se debe fundamentalmente a diferentes factores entre los que destacan los factores editoriales y comerciales, factores legales, factores literarios, así como factores que carácter estético y de lecturabilidad y legibilidad.

Nos hacemos eco de la relevancia del libro durante la Edad Moderna como eje globalizador, ya que sirve para transferir conocimientos a otras culturas y entornos, dando nacimiento al primer producto comunicativo de carácter globalizado mediante la inserción de contenidos en varios idiomas. Destacando igualmente la falta de información referida en el diseño de fuentes tipográficas no latinas.

30 Revista El Correo. “De tipos Móviles. El Arte de Imprimir” Julio 1988. 


\section{BIBLIOGRAFÍA}

AAKER, D. Construir Marcas Poderosas, Ediciones Gestión 2000, Barcelona 2002.

ABOUSSOUAN, C. "Los albores de la impresión en árabe" en El Correo París: Unesco, julio 1988. p. 25-27. Disponible en web: <http://unesdoc.unesco.org/images/0007/000796/079609so.pdf>

BORAO, D. GERÓNIMO. La imprenta en Zaragoza: con noticias preliminares sobre la imprenta en general. Imprenta y librería de Vicente Andrés, Cuchillería, no 42, Zaragoza 1860.

CORNEJO, R. China. Estudios y ensayos en honor a Flora Botton Beja, Ediciones El Colegio de México, México 2012.

CORREAS, G. Vocabulario de refranes y frases proverbiales, Ed. Louis Combet, rev. Robert Jammes y Maite Mir-Andreu. Madrid: Castalia 1627. (Nueva Biblioteca de Erudición y Crítica, 19).

COVARRUBIAS OROZCO, S. Tesoro de la Lengua Castellana o Española, Impresor del Rey N.S. Luis Sanchez, Madrid 1611.

ECO, U. Signo, Ediciones Labor, Barcelona 1988.

HERNÁNDEZ MUÑOZ, S. “La tipografía y los monstruos” en i+Diseño Vol. 10, Málaga, abril 2015.

LARRAÑAGA RAMIREZ, M. De la letra a la página, Universidad Autónoma Metropolitana, División de Ciencias y Artes para el Diseño, México 1993.

LAUFER, R. “'́esprit de la lettre. D’une lecture matérielle des libres” en Le Débat no 22, 1982, p. 146-159.

LÓPEZ POZA, S. “Los libros de emblemas y la imprenta” en Lectura y Signo ํㅜ 1, Coruña: Universidad de la Coruña, 2006, p. 177-199.

MOLES, A. y JANISZEWSKI, L. Grafismo Funcional, Ediciones CEAC, Barcelona 1990.

MUNTADA TORRELLAS, A. "Del Misal Rico de Cisneros y de la Biblia Políglota Complutense o bien del manuscrito al impreso" en LOCVS AMCENVS nํㅜ 5, Barcelona: Departament d'Art. Universitat Autònoma de Barcelona, 2000-2001, p. 77-99.

NAYAR, L. "Códices Precolombinos" en Serie Documentos de trabajo ํㅡㄹ, Consultora de Ciencias de la Información, Buenos Aires 2009.

NEEDHAM, J. De la ciencia y la tecnología chinas, Siglo XXI Editores, México 2004.

ONG, W. Oralidad y escritura. Tecnologías de la palabra, Fondo de Cultura Económica. México 2006.

REVUELTA GUERRERO, C. "Objetos de estudio para una historia de la traducción: textos generados en la práctica de la misión en China y Filipinas, (s. XVI-XIX)" en In-Traduções, marzo 2014, vol. 6, Florianópolis, p. 34-51.

SARDELLI, Ma ANTONELLA. Las ediciones del Vocabulario de refranes y frases proverbiales (1627) de Gonzalo Correas en Culturas Populares, Revista Electrónica, ํㅜ 6, 2008, p. 16. <http://www.culturaspopulares. org/textos6/articulos/sardelli.pdf> 
SATUÉ, E. El diseño gráfico. Desde los orígenes hasta nuestros días, Alianza Editorial-Alianza Forma, Madrid 2010.

TORNÉ, E. "Arquitectura tipográfica del libro en el Siglo de Oro" en Erebea, Vol. 2, Universidad de Alcalá, Madrid 2012, p. 77-108. 